\title{
Two Years' Experience in Keratoconus Treatment using Collagen Cross-linking
}

\author{
${ }^{1}$ Dimitrii Dementiev, ${ }^{2}$ Maria Sysoeva, ${ }^{3}$ Anna Shipunova
}

\begin{abstract}
Purpose: To evaluate safety, efficacy, and stability of crosslinking $(C L X)$ procedure as a method for keratoconus treatment in the I and II stage of disease.
\end{abstract}

Materials and methods: Twenty eyes of 15 patients (13 males, 2 females, average age 31 years) with keratoconus I stage (13 eyes) and II stage ( 2 eyes) (by Krumeich classification) were treated by CLX procedure, using riboflavin Medio Cross for standard CLX); riboflavin Medio Cross TE for transepithelial CLX was used to treat keratectasia after previous keratorefractive surgery; in all the cases UV CBM X linker (Vega, CSO) was used. The study included evaluation of uncorrected visual acuity (UCVA), best-corrected visual acuity (BCVA) pre- and postoperative, pachymetry (central cornea thickness) (Visante OCT, Zeiss) pre- and postoperative, total astigmatism pre- and postoperative, using keratotopography (Atlas, Zeiss). Diagnosis and analysis have been performed at the International Center for Ophthalmology in Moscow, Russian Federation, since 2012 to 2014 years. Follow-up period was from 1 to 24 months.

Results: Average UCVA preoperative was 0.4 (Decimal), and average BCVA was 0.64. Average UCVA postoperative was 0.49 ; average BCVA was 0.66 . Total astigmatism preoperative was $2.81 \mathrm{D}$; total astigmatism postoperative $2.80 \mathrm{D}$. Central cornea thickness (CCT) preoperative $454 \mathrm{mkm}$; CCT postoperative $447 \mathrm{mkm}$.

Conclusion: Cross-linking indicated safety, stability, and efficacy for treatment of I and II stage keratoconus at the end of follow-up period. Cross-linking is not effective in the treatment of II and III stage of disease. Further study is required.

Keywords: Cross-linking, Keratectasia, Keratoconus.

How to cite this article: Dementiev D, Sysoeva M, Shipunova A. Two Years' Experience in Keratoconus Treatment using Collagen Cross-linking. Int J Kerat Ect Cor Dis 2017;6(1):11-13.

Source of support: Nil

Conflict of interest: None

\section{INTRODUCTION}

As known, keratoconus is a degenerative, noninflammatory progressive cornea disease that results in thinning, protrusion in central part of a cornea, myopic shift,

\footnotetext{
${ }^{1-3}$ Ophthalmologist

1-3 International Center for Ophthalmology, Moscow, Russian Federation

Corresponding Author: Maria Sysoeva, Ophthalmologist International Center for Ophthalmology, Moscow, Russian Federation, Phone: +74959389779, e-mail: maria79ko@gmail.com
}

and irregular astigmatism. ${ }^{1-4}$ Nowadays, the etiology of keratoconus and other keratectasias is not known. According to earlier reviews, gene mutation may result in keratoconus. ${ }^{5,6}$ Active progression is in $20 \%$ of patients; as a rule, beginning of disease occurs in teenagers and young men. Progress of disease results in vision impairment and impossibility of glasses correction.

\section{DIAGNOSTIC METHODS}

The main method for early diagnostic of keratoconus is computerized keratotopography; in connection with pachimetry, aberrometry, autorefractometry, slit-lamp examination, and anamnesis, it is possible to suspect and diagnose keratoconus in majority of cases. ${ }^{7}$

\section{STAGES OF KERATOCONUS TREATMENT}

The treatment of keratoconus consists of successive steps.

At stages I and II of keratoconus we use UV stability of cross-linking (CLX) to stop progression and stabilization of keratotopography.

In 3 to 4 months post CLX, on stability of refraction, keratotopography, and pachimetry we performed implantation of intrastromal segments (we prefer INTACS) for the correction of cone shape in case of high irregularity or prescribe glasses if astigmatism is low. ${ }^{8}$

The next step is vision correction. In case of lens opacification we perform phacoemulsification with toric customized intraocular lens (IOL) implantation (AT Torbi 709M), or (if a lens is clear) we implant posterior phakic IOL.

At III and IV stage, as a rule, penetrating keratoplasty (PKP) is indicated.

\section{PRINCIPLE OF METHOD}

Corneal collagen cross-linking is relatively a new method for early keratoconus treatment. The mechanism of procedure: Photosensitive substance-riboflavin is activated under UV-A illumination and photopolymerization of collagen fibers was done, which leads to cornea's strength. ${ }^{1-4}$

\section{GOAL}

Our purpose was to evaluate safety, efficacy, and stability of CLX procedure as a method for keratoconus treatment in I and II stage of disease. 


\section{MATERIALS AND METHODS}

Our study was from 2012 to 2014 years and included 20 eyes of 15 patients (13 males, 2 females, average age 31 years) with I (13 eyes) and II (2 eyes) stage of keratoconus (by Krumeich classification). In 17 eyes the diagnosis was primary keratoconus I and II stage, and in 3 eyes were after previous keratorefractive surgery (LASIK, RK). Two patients reported about family history of keratoconus. Systemic diseases: Neurodermatitis (2 patients); herpes simplex virus (2 patients). All patients were performed standard pre- and postoperative examination: Evaluation of uncorrected visual acuity (UCVA), best-corrected visual acuity (BCVA), computerized pachymetry (central cornea thickness) (Visante OCT, Zeiss), total astigmatism, using computerized keratotopography (Atlas, Zeiss). Diagnosis and analysis were performed at International Center for Ophthalmology in Moscow, Russian Federation. Follow-up period was from 1.5 to 24 months. Sixteen eyes with primary keratoconus were treated by CLX procedure, using riboflavin Medio Cross for standard CLX, and 3 eyes after previous keratorefractive surgery were undergone transepithelial CLX, using riboflavin Medio Cross TE; in all the cases UV CBM $\mathrm{X}$ linker (Vega, CSO) was used.

\section{Preoperative Assessment}

Pilocarpine $2 \%$ twice and lidocaine $4 \%$ three times for 30 minutes.

\section{SURGICAL TECHNIQUE}

Standard CLX was performed routinely with deepithelization, followed by riboflavin instillation every 2 minutes during half an hour and followed by UV-A illumination of 5 to 6 steps for 30 minutes. After operation the contact lens (Biomedics 55 Evolution) was put on the cornea. Transepithelial CLX was performed similar without epithelial removing.

\section{Postoperative Assessment}

In postoperative period all patients used Indocollir and Tobrex before contact lens removing (5-7 days after operation) and Tobradex with Natural tear drops after full epithelial recover. Postoperative follow-up was the following day, 1 week, 1 month, 3 to 4 months, 6 months, 1 year, and 2 years.

\section{Complication}

There were no severe complications. ${ }^{10}$ Haze was in four eyes during 3 months.

\section{RESULTS}

All of the patients reported about vision improvement at the end of follow-up period. Average UCVA preoperative was 0.4 (Decimal); average BCVA preoperative was 0.64. Average UCVA postoperative was 0.49 ; average BCVA postoperative was 0.66 . Total astigmatism preoperative was $2.81 \mathrm{D}$; total astigmatism postoperative was $2.80 \mathrm{D}$. In 4 patients ( 5 eyes) total astigmatism went up $0.44 \mathrm{D}$ in 1 to 4 months postoperative with following stabilization at the end of follow-up period. In one patient with II and III stage, in 12 months postoperative total astigmatism went up $3.96 \mathrm{D}$, so he had acute corneal hydrops on his other eye and was undergone PKP. Central cornea thickness (CCT) preoperative was $454 \mathrm{mkm}$; CCT postoperative was $447 \mathrm{mkm}$.

\section{CONCLUSION}

We found stable results (limited improvement) of UCVA, BCVA, total astigmatism, and CCT (changes in CCT are nonclinically significant). There was no progression of the disease during follow-up period.

Our study showed prevalence of keratoconus in male, young patients, inherited predisposition to disease, interaction between keratoconus and viral, and dermatological diseases.

We conclude that CLX is a safe, effective method to treat I and II stage of primary keratoconus and keratoconus post previous refractive surgery, but it is not effective to treat II and III stage of disease.

Further study of CLX is required.

\section{REFERENCES}

1. Theuring A, Spoerl E, Pillunat LE, Raiskup F. Corneal collagen cross-linking with riboflavin and ultraviolet - a light in progressive keratoconus. Ophthalmologe 2015 Feb;112(2):140-147.

2. Kymionis GD, Grentzelos MA, Kankariya VP, Liakopoulos DA, Portaliou DM, Tsoulnaras KI, Karavitaki AE, Pallikaris AI. Safety of high-intensity corneal collagen crosslinking. J Cataract Refract Surg 2014 Aug;40(8):1337-1340.

3. De Bernardo M, Capasso L, Tortori A, Lanza M, Caliendo L, Rosa N. Trans epithelial corneal collagen crosslinking for progressive keratoconus: 6 months follow up. Cont Lens Anterior Eye 2014 Dec;37(6):438-441.

4. Beckman Rehnman J, Behndig A, Hallberg P, Lindén C. Increased corneal hysteresis after corneal collagen crosslinking: a study based on applanation resonance technology. JAMA Ophthalmol 2014 Dec;132(12):1426-1432.

5. Vincent AL, Jordan CA, Cadzow MJ, Merriman TR, McGhee $\mathrm{CN}$. Mutations in the zinc finger protein gene, ZNF469, contribute to the pathogenesis of keratoconus. Invest Ophthalmol Vis Sci 2014 Aug 5;55(9):5629-5635.

6. Synowiec E, Wojcik KA, Izdebska J, Blasiak J, Szaflik J, Szaflik JP. Polymorphisms of the apoptosis-related FAS and FAS ligand genes in keratoconus and Fuchs' endothelial corneal dystrophy. Tohoku J Exp Med 2014;234(1):17-27.

7. Sezgin Akçay BÄ, Ozgürhan EB, Bozkurt E, Kurt T, Yildirim Y, Coşar MG, Yıldırım A, Canan J, Akkan U, Demirok A. 
Evaluation of pachymetric measurements with scheimpflug photography-based system and optical coherence tomography pachymetry at different stages of keratoconus. J Ophthalmol 2014;2014:719205.

8. Elbaz U, Shen C, Lichtinger A, Zauberman NA, Goldich Y, Ziai S, Rootman DS. Accelerated versus standard corneal collagen crosslinking combined with same day phototherapeutic keratectomy and single intrastromal ring segment implantation for keratoconus. Br J Ophthalmol 2015 Feb;99(2):155-159.
9. Kamiya K, Shimizu K, Kobashi H, Igarashi A, Komatsu M, Nakamura A, Kojima T, Nakamura T. Three-year followup of posterior chamber toric phakic intraocular lens implantation for the correction of high myopic astigmatism in eyes with keratoconus. Br J Ophthalmol 2015 Feb;99(2): 177-183.

10. Lam FC, Georgoudis P, Nanavaty MA, Khan S, Lake D. Sterile keratitis after combined riboflavin-UVA corneal collagen cross-linking for keratoconus. Eye (Lond) 2014 Nov;28(11):1297-1303. 